\title{
Integration of Strategic Highway Research Program 2 Products within the Entire Civil Engineering Curriculum
}

Dr. Yusuf A Mehta, Rowan University

Dr. Mehta is a Professor at the Department of Civil and Environmental Engineering at Rowan University and Director of Center for Research and Education in Advanced Transportation Engineering Systems (CREATEs). Dr. Mehta has extensive experience in teaching pavement materials and pavement systems. Dr. Mehta has published several technical and educational papers in leading professional organizations.

Dr. Parth Bhavsar, Rowan University

Dr. Ayman Ali, Rowan University 


\title{
Integration of Strategic Highway Research Program 2 Products Within an ABET-Accredited Civil Engineering Curriculum
}

\begin{abstract}
The Department of Civil and Environmental Engineering at Rowan University, led by staff and faculty who teach classes in transportation engineering, modified and refined the current civil engineering curricula by incorporating several (i.e., 17) Strategic Highway Research Program 2 (SHRP 2) solutions and products. The basic philosophy of the authors was to incorporate the SHRP 2 products as next generation tools to address existing and future transportation issues in addition to teaching the fundamentals of relevant subject matter, which is in line with the department's mission to prepare the next generation of civil engineering professionals. Each selected SHRP 2 product has become an inherent part of the course module. These were taught immediately after the relevant theoretical content was presented in the course. Furthermore, the authors re-emphasized these concepts using SHRP 2 as a tool for a seamless transition from theory to practice. A pre-survey and post-survey were conducted to determine the impact of introducing SHRP 2 modules within the courses. The results of the pre-and postsurvey are presented. A detailed framework on how to seamlessly integrate SHRP 2 products through the entire civil engineering curriculum in other institutions is also presented.
\end{abstract}




\section{INTRODUCTION}

The second Strategic Highway Research Program (SHRP 2) was initiated by Congress in order to find solutions to three national transportation challenges: (1) increase highway safety to achieve the target of zero fatality on US highways; (2) increase mobility and reduce traffic congestion, and (3) how to maintain existing infrastructure through renewal and maintenance of roads and bridges. Over the course of several years, SHRP 2 has funded more than 100 research projects. These projects were developed to address national level transportation challenges using state and/or local level case studies. SHRP 2 research results have been disseminated to the public through a series of solutions (in the form of guidance documents and/or online/offline software). Through the implementation of SHRP 2 products, it is expected that the transportation community will find more efficient solutions to strengthen the Nation's highway system.

In order to increase awareness of the SHRP 2 research products, the agency has established the SHRP 2 Education Connection program. This program focuses on incorporating SHRP 2 products into college-level lesson plans and curricula. This program also advances the efforts of bringing state of the art to current state of the practice and extending the benefits of SHRP 2 products to the next generation of transportation professionals. However, in order to successfully incorporate SHRP 2 products into academia, the agency must collaborate with universities. Therefore, collaboration between SHRP 2 and universities is essential to ensure success of the Education Connection program. As a solution, this paper proposes an approach to integrate SHRP 2 products into the civil engineering curricula. These courses not only include junior transportation engineering courses and transportation electives, but also introductory freshman courses and a class in statistical applications in civil engineering.

\section{STUdy OBJECTIVES}

The objective of this study was to develop and evaluate a strategy for integrating selected SHRP 2 products into civil engineering curricula by preparing course work materials, exams, and course evaluation materials. It is believed that the proposed approach will benefit universities interested in refining their curricula in the future.

\section{OVERVIEW OF SELECTED SHRP 2 PRODUCTS}

SHRP 2 products are divided into four major areas; (1) renewal, (2) reliability, (3) capacity, and (4) safety. The renewal products focus on maintaining existing infrastructure and developing innovative solutions for rapid renewal of the transportation system. Reliability products focus on maintaining and improving operations and management of the existing transportation system. The capacity products focus on developing products that support intelligent and quick decision making to design new highway capacity. The safety products focus on improving understanding of driver behavior and relationship of safety performance with other highway design, planning, and implementation factors. For this study, the following SHRP 2 products were integrated into the Rowan University civil engineering curricula:

- SHRP 2 Renewal Products

- Innovative Bridge Designs for Rapid Renewal (R04).

- Precast Concrete Pavement (R05).

- Nondestructive Testing for Concrete Bridge Decks (R06A).

- Technologies to Enhance Quality Control on Asphalt Pavements - Infrared (IR) Imaging Only (R06C).

○ Service Life Design for Bridges (R19A). 
○ New Composite Pavement Systems (R21).

O Pavement Renewal Solutions (R23).

- SHRP 2 Reliability Products

○ Guidelines for Incorporating Reliability Performance Measures into Travel Models (L04).

- National Traffic Incident Management Responder Training Program (L12/L32A/L32B).

- Framework for Improving Travel-Time Reliability (L17/L13A).

- Regional Operations Academy (L36).

- SHRP 2 Capacity Product

O PlanWorks: Better planning, Better projects (C01)

- Performance Measures for Highway Capacity Decision Making (C02)

- Integrating Freight Considerations into the Highway Capacity Planning Process (C15)

○ Transportation Visioning for Communities (C08)

- Economic Analysis Tools (C03/C11).

- Advanced Travel Analysis Tools for Integrated Travel Demand Modeling (C04/C05/C16).

These products were integrated from freshman year to graduate level courses as explained in the following section.

\section{Proposed SHRP 2 Products Vertical InTEgration ApProach}

The proposed integration approach (illustrated in Figure 1 below) involves incorporating the selected SHRP 2 products into multiple civil engineering courses offered in all four years of the undergraduate curriculum and in graduate courses. The approach follows a vertical integration scheme which first introduces the SHRP 2 products to freshman undergraduate students and then presents relevant SHRP 2 products to the junior level classes with a brief review session at the beginning to refresh their memory. The vertical integration scheme then presents relevant SHRP 2 products in senior/graduate level classes. The depth of technical content of the SHRP 2 modules increases from freshman to senior/graduate levels-building on the information provided in previous year(s). Furthermore, selected senior and graduate level courses also focus on applications of the SHRP 2 products to reinforce learning and help students achieve mastery of tasks and SHRP 2 products. While Figure 1 describes the details of integrating SHRP 2 products, the following subsections provide the specific steps undertaken to integrate SHRP 2 products in particular courses. It is noted that the discussion is limited only to courses that were taught during the Fall 2015 semester. Since the Fall 2015 semester was the first trial-run for the proposed strategy, the SHRP 2 instructions at each level started with an introduction of the SHRP 2 program.

\section{Sophomore Course: Civil Engineering Systems}

Civil Engineering Systems is a required sophomore level course typically offered in the fall of the sophomore year. This class meets for 150 minutes every week in which the students learn about probability, statistics, reliability and uncertainty, and its relevancy to the different fields of civil engineering, such as transportation, hydraulics, and environmental engineering.

In the Fall 2015 semester, a SHRP 2 reliability product was incorporated in this course. Since this is the first time any of the selected SHRP 2 products were introduced in this course, the class began with a brief overview (i.e., the first 10 minutes of the lecture) of SHRP 2 products. The remainder of the lecture covered SHRP 2 Reliability Product L04: Incorporating 
Reliability Performance Measures in Operations and Planning Modeling Tools. The fundamental concept of reliability and how it relates to pavement design and travel time were explained in the beginning followed by the importance and impacts of SHRP 2 product L04.

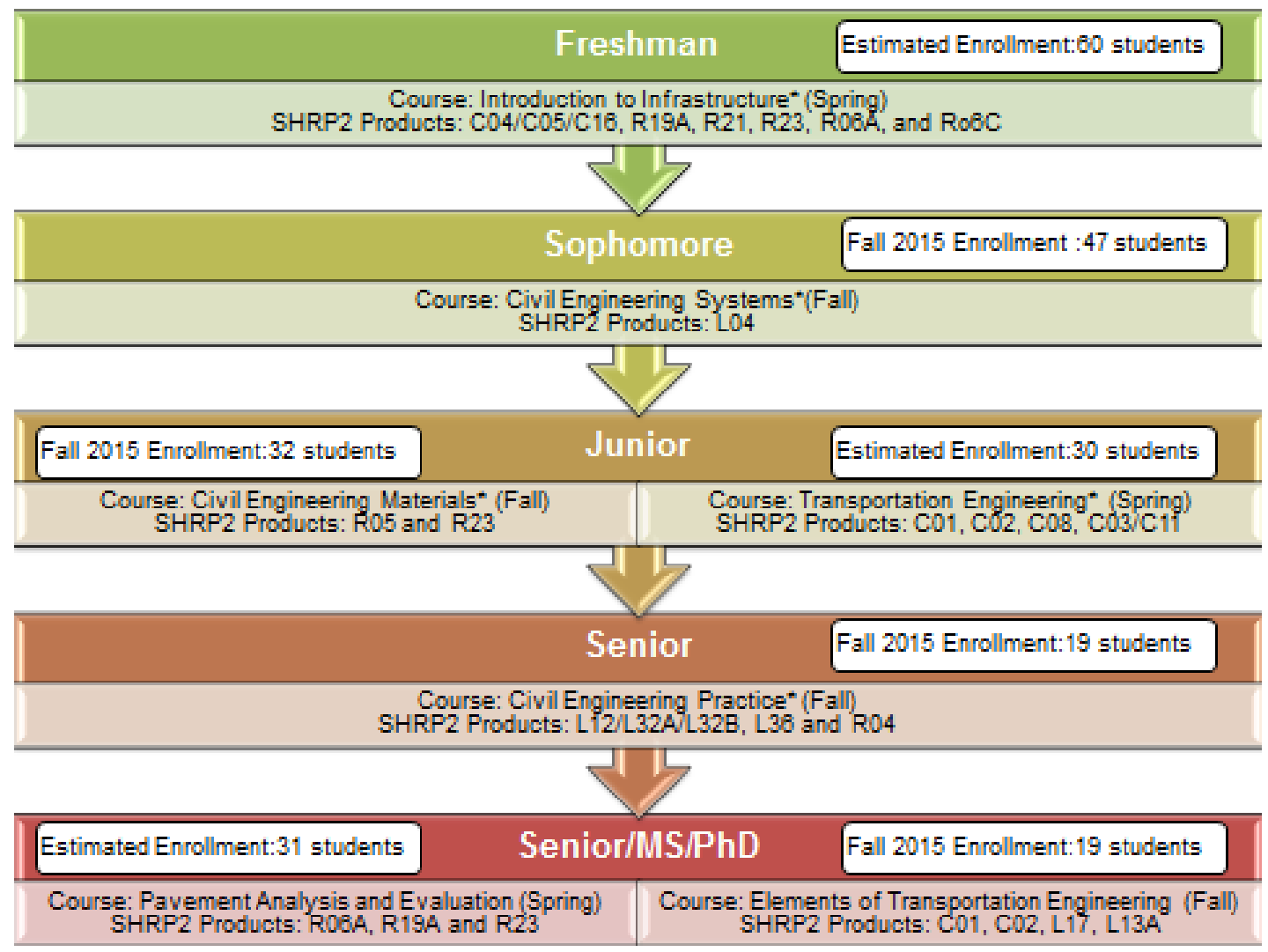

Figure 1: Illustration of Vertical SHRP 2 Products Integration Approach.

\section{Junior course: Civil Engineering Materials}

Civil Engineering Materials is a required junior level course offered in the fall of the junior year. This class meets for 150 minutes of lecture and 150 minutes of laboratory every week. In this course, the students learn about aggregates, cement, cement concrete, asphalt, and asphalt concrete. They learn cement concrete and Superpave mix design and conduct experiments in the laboratory on these materials.

SHRP 2 products, such as Precast Concrete Pavements (R05) and Pavement Renewal Solutions (R23), were incorporated through a 75-minute module as a part of this course. This module emphasized the importance of appropriate selection of different materials and attention to construction practices.

Senior Course: CE Practice

CE Practice is a required senior level course. This class meets for 150 minutes every week. In this course, the instructor emphasizes practical aspects of civil engineering. Speakers from industry and academia with expertise in various fields within civil engineering such as structure and transportation are invited to share their experience and explain the practical aspects of understanding plans and performing traffic impact studies. 
In the Fall 2015 semester, the instructor introduced SHRP 2 products with a module titled "bringing everything together." The module started by connecting different concepts covered throughout the entire curriculum with SHRP 2 products. Then the importance of these products was discussed followed by the impacts of these products on the current and future society.

\section{Senior/Grad Course: Elements of Transportation Engineering}

The goal of this course is to teach principles of traffic engineering, with emphasis on practical applications. The class, Elements of Transportation Engineering, includes highway capacity analysis, design of signalized and unsignalized intersections, as well as intelligent transportation systems (ITS) technologies and traffic simulation. This course was offered in the Fall 2015 semester and the following SHRP 2 products were introduced. It should be noted that most of these tools are now part of a larger web resource which can be accessed by visiting www.econ-works.org.

1) Transportation for Communities-Advancing Projects through Partnerships (TCAPP) [Plan Works, C01]: The most significant outcome of this project is a PlanWorks web resource which provides linkage to several tools. The instructor introduced several tools using this website. PlanWorks can be accessed by visiting www.econ-works.org.

2) Transportation-Visioning for Communities (T-VIZ) [C08]: This tool was introduced after the basic introduction of critical thinking and visioning for transportation. Students were also encouraged to use this tool for a class project. This tool is now a part of application section of the web resource PlanWorks with the title "Visioning and Transportation."

3) Performance Measurement Framework for Highway Capacity Decision Making [C02]: This tool can be utilized to teach the importance of selecting a 'few good measures' for any transportation project. In addition, the students were encouraged to utilize this tool for their individual and group projects. This tool is now a part of the application section of the combined web resource PlanWorks with the title, "Performance Measures."

4) Transportation Project Impact Case Studies (TPICS) [C03/C11]: This tool can be introduced as a part of system impacts and benefit-cost analysis modules. Students were encouraged to utilize this tool to find case studies which were similar to their class project. This tool is now a part of web resource EconWorks and can be accessed by visiting www.econ-works.org.

5) SmartGAP [C04, C05, C16]: This tool can be utilized for several modules such as critical thinking and decision-making, demand analysis and system impacts. This tool is now a part of the web resource EconWorks and can be accessed by visiting www.econ-works.org.

6) Integrating Freight Considerations into the Highway Capacity Planning Process (C15): This tool can be utilized to explain the importance of freight movement and how that will impact modeling of a transportation network and simulating various 'what-if' scenarios for travel demand forecasting.

\section{Evaluation of EfFectiveness of Proposed ApProach}

The effectiveness of the proposed SHRP 2 integration approach was evaluated by first incorporating (i.e., teaching) various products into the Civil Engineering curricula and conducting pre- and post-teaching surveys to evaluate the impact of SHRP 2 products on existing courses. It is noted that these surveys were handed out to the students in addition to the Accreditation Board for Engineering and Technology (ABET) required course evaluation surveys for each course.

The pre- and post-teaching surveys were conducted at the beginning (i.e., before discussing SHRP 2 products) and after introducing a SHRP 2 products for each course. The 
surveys were also designed to be short with only 5 to 6 questions targeting the extent of students' SHRP 2 product knowledge as well as their view on the importance of these products. Tables 1 and 2 present an example of each of the pre- and post-teaching survey given to the students.

Table 1: An Example of the Developed Pre-Teaching Survey.

Pre-Survey (Questions Pertaining to Course)

Question No. 1: Please specify how much you agree/disagree with the following statement:

I have prior knowledge of the Strategic Highway Research Program 2

(SHRP 2) products. These products were introduced to me in previous courses.

(1) Strongly Disagree

(2) Disagree

(3) Neutral

(4) Agree

(5) Strongly Agree

Question No. 2: Please specify how much you agree/disagree with the following statement: I have used SHRP 2 products for my projects/assignments in my previous courses.

(1) Strongly Disagree

(2) Disagree

(3) Neutral

(4) Agree

(5) Strongly Agree

Question No. 3: Please specify how much you agree/disagree with the following statement: SHRP 2 products are highly innovative tools that resulted from research studies funded by the U.S. Department of Transportation. These products offer the opportunity to bring state-of-the-art practice to the class room. I am highly interested in learning these courses as a part of this course.

(1) Strongly Disagree

(2) Disagree

(3) Neutral

(4) Agree

(5) Strongly Agree

Question No. 4: Please select how likely are you to use SHRP 2 products in your class project.

Based on your current knowledge of SHRP 2 product, how likely will you be willing to use these products in your current and future course projects, assignments, and real-world projects?

(1) Extremely Likely

(2) Likely

(3) Maybe

(4) Unlikely

(5) Extremely Unlikely

Question No. 5: Please specify how much you agree/disagree with the following statement: Based on my current knowledge of SHRP 2 products, I strongly believe that these products will improve my skills as a transportation engineer.

(1) Strongly Disagree

(2) Disagree 

(3) Neutral
(4) Agree
(5) Strongly Agree

Table 2: An Example of the Developed Post-Teaching Survey.

\section{Post-Survey (Questions Pertaining to Course)}

\section{Introduction:}

The instructor presented SHRP 2 products in the class. These products can be used for various transportation engineering and planning applications. Based on the knowledge you gained about SHRP 2 products, please answer the following questions:

Question No. 1: Please specify how much you agree/disagree with the following statement: I had the necessary background regarding SHRP 2 products and research projects from previous course I have taken.
(1) Strongly Disagree
(2) Disagree
(3) Neutral
(4) Agree
(5) Strongly Disagree

Question No. 2: Please specify how much you agree/disagree with the following statement:

I will use SHRP 2 products in my future class(s) assignments and real-world projects.
(1) Strongly Disagree
(2) Disagree
(3) Neutral
(4) Agree
(5) Strongly Agree

Question No. 3: Please specify how much you agree/disagree with the following statement: I am interested in learning about SHRP 2 products in the classes I intend to take in the future.
(1) Strongly Disagree
(2) Disagree
(3) Neutral
(4) Agree
(5) Strongly Agree

Table 2 (Continued): An Example of the Developed Post-Teaching Survey. Post-Survey (Questions Pertaining to Course)

Question No. 4: Please specify how much you agree/disagree with the following statement:

I believe that SHRP 2 products will increase the quality of my class assignments/projects and enhance my skill level as a transportation engineer.

(1) Strongly Disagree

(2) Disagree 
(3) Neutral

(4) Agree

(5) Strongly Disagree

\section{Question No. 5: Select the three most interesting SHRP 2 products}

From the following list of SHRP 2 products, please select the most interesting products or those you would consider for further research investigation. Please select at least three (3) products from the following list:

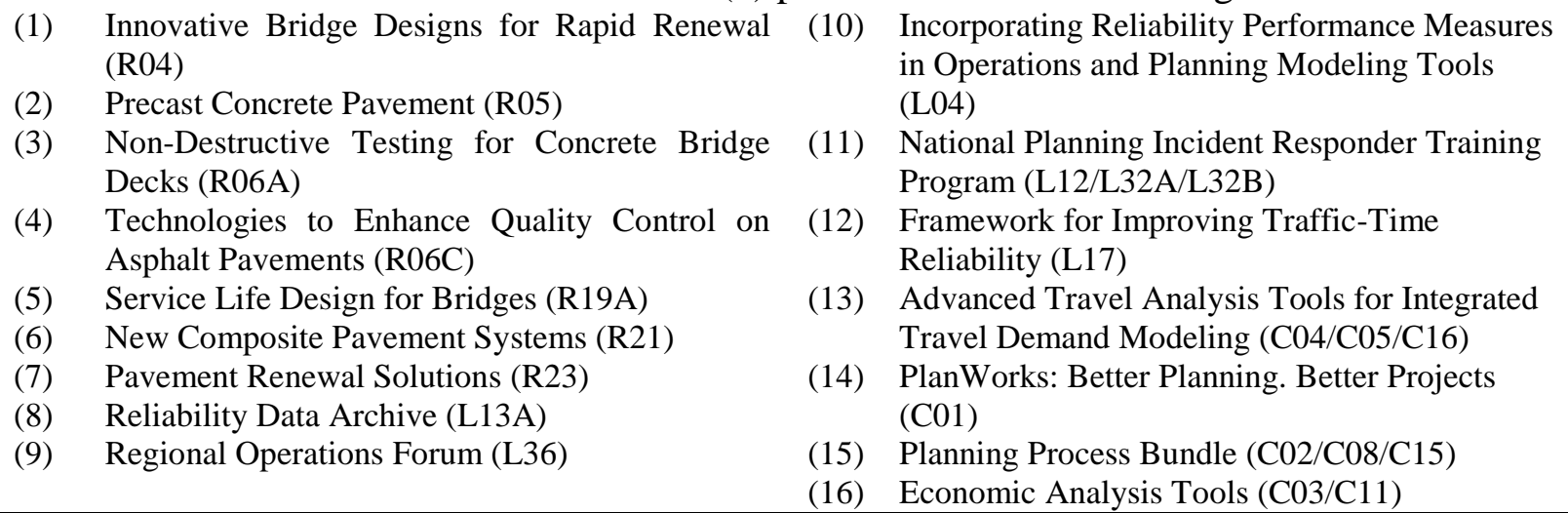

\section{Question No. 6: Select a SHRP 2 tool/product for further consideration}

From the following list of SHRP 2 products, please select a tool or a product that you will definitely consider for further research/investigation:
(1) Innovative Bridge Designs for Rapid Renewal (R04)
(2) Precast Concrete Pavement (R05)
(3) Non-Destructive Testing for Concrete Bridge Decks (R06A)
(4) Technologies to Enhance Quality Control on Asphalt Pavements (R06C)
(5) Service Life Design for Bridges (R19A)
(6) New Composite Pavement Systems (R21)
(7) Pavement Renewal Solutions (R23)
(8) Reliability Data Archive (L13A)
(9) Regional Operations Forum (L36)

(10) Incorporating Reliability Performance Measures in Operations and Planning Modeling Tools (L04)

(11) National Planning Incident Responder Training Program (L12/L32A/L32B)

(12) Framework for Improving Traffic-Time Reliability (L17)

(13) Advanced Travel Analysis Tools for Integrated Travel Demand Modeling (C04/C05/C16)

(14) PlanWorks: Better Planning. Better Projects (C01)

(15) Planning Process Bundle (C02/C08/C15)

(16) Economic Analysis Tools (C03/C11)

\section{IMPLEMENTATION RESULTS}

This section presents the results obtained after conducting the pre- and post-teaching surveys. It is noted that the results presented in this section are limited to classes in which SHRP 2 products were incorporated and taught in the Fall 2015 semester. It is also worth mentioning that these classes had engineering students from various levels (i.e., sophomore through senior/grad levels).

Table 3 shows a list of courses taught in the Fall 2015 semester and the number of survey responses obtained for each course. As can be seen from this table, the SHRP 2 products were introduced to students taking CE Systems (sophomore level), CE Materials (junior level), CE Practice (senior level) and Elements of Transportation Engineering (senior/grad level). Since this was the first time the students in these classes were introduced to SHRP 2 products, the instructors of SHRP 2 modules started each module with a brief introduction of the SHRP 2 program. This was necessary to ensure that all students from the various academic levels were 
introduced to these products in the same fashion which in turns facilitates analyzing the results collectively. In addition, Table 3 shows that a high number of responses (in some cases the whole class) was obtained from both the pre- and post-teaching surveys.

Table 3: Course Taught in the Fall 2015 Semester and Survey Responses Received.

\begin{tabular}{lcccc}
\hline \multicolumn{1}{c}{ Course title } & Level & $\begin{array}{c}\text { No. of Responses } \\
\text { (Pre-Teaching } \\
\text { Survey) }\end{array}$ & $\begin{array}{c}\text { No. of Responses } \\
\text { (Post-Teaching } \\
\text { Survey) }\end{array}$ & $\begin{array}{c}\text { Implementa- } \\
\text { tion }\end{array}$ \\
\hline CE Systems (CES) & Sophomore & 47 & $45^{*}$ & Paper \\
CE Materials (CEM) & Junior & 32 & $32^{*}$ & Paper \\
CE Practice (CEP) & Senior & 40 & $29^{*}$ & Paper \\
$\begin{array}{l}\text { Element of Transportation } \\
\text { Engineering (ETE) }\end{array}$ & $\begin{array}{c}\text { Senior/MS/ } \\
\text { Ph.D. }\end{array}$ & 19 & $18^{* *}$ & Online \\
$\begin{array}{l}* \text { "Immediately after teaching SHRP 2 module } \\
\text { After one (1) week of teaching SHRP 2 module }\end{array}$ & & &
\end{tabular}

Figure 2 below presents the percentage breakdown of responses obtained for PreTeaching Survey Question No. 1. As can be seen from this figure, the majority of surveyed undergraduate and graduate students had no prior knowledge (i.e., either answered strongly disagree, disagree, or neutral) of SHRP 2 program or its products. These results were expected because this study is in fact the first time the surveyed students were introduced to SHRP 2 products (i.e., SHRP 2 was not a part of the civil engineering curricula before this study). The results presented in Figure 2 also indicate that during the trial run of this seven-class series, it would be prudent to briefly introduce the students to the SHRP 2 program before actually discussing a specific SHRP 2 product.

Figure 3 presents the responses for the pre-teaching and post-teaching survey questions related to students' interest in learning about SHRP 2 products. As shown in Figure 3a and 3b, the majority of the surveyed students, regardless of their academic level, generally expressed their interest in learning about SHRP 2 products (i.e., answered with agree or strongly agree). However, comparing the results between the pre- and post-teaching surveys for the classes (i.e., different academic levels) shows slight differences in the responses of the students with the general trend being a slight disinterest before learning about SHRP 2 products (Figure 3a or PreTeaching Survey) to more interest after learning about the products (Figure $3 b$ or Post-Teaching Survey). To elaborate more with the example of sophomore students enrolled in the Civil Engineering Systems (CES) class; about $4.3 \%$ of the students in this class did not express any interest in learning about SHRP 2 products; however, after attending the SHRP 2 module, those students indicated that they are interested in learning about SHRP 2 products. The same trend can also be observed for other classes (or academic levels) with slight differences in responses. To summarize the results presented in Figure 3, the implemented approach was a success because students' interest in learning about SHRP 2 products increased after implementing the proposed SHRP 2 vertical integration approach. 


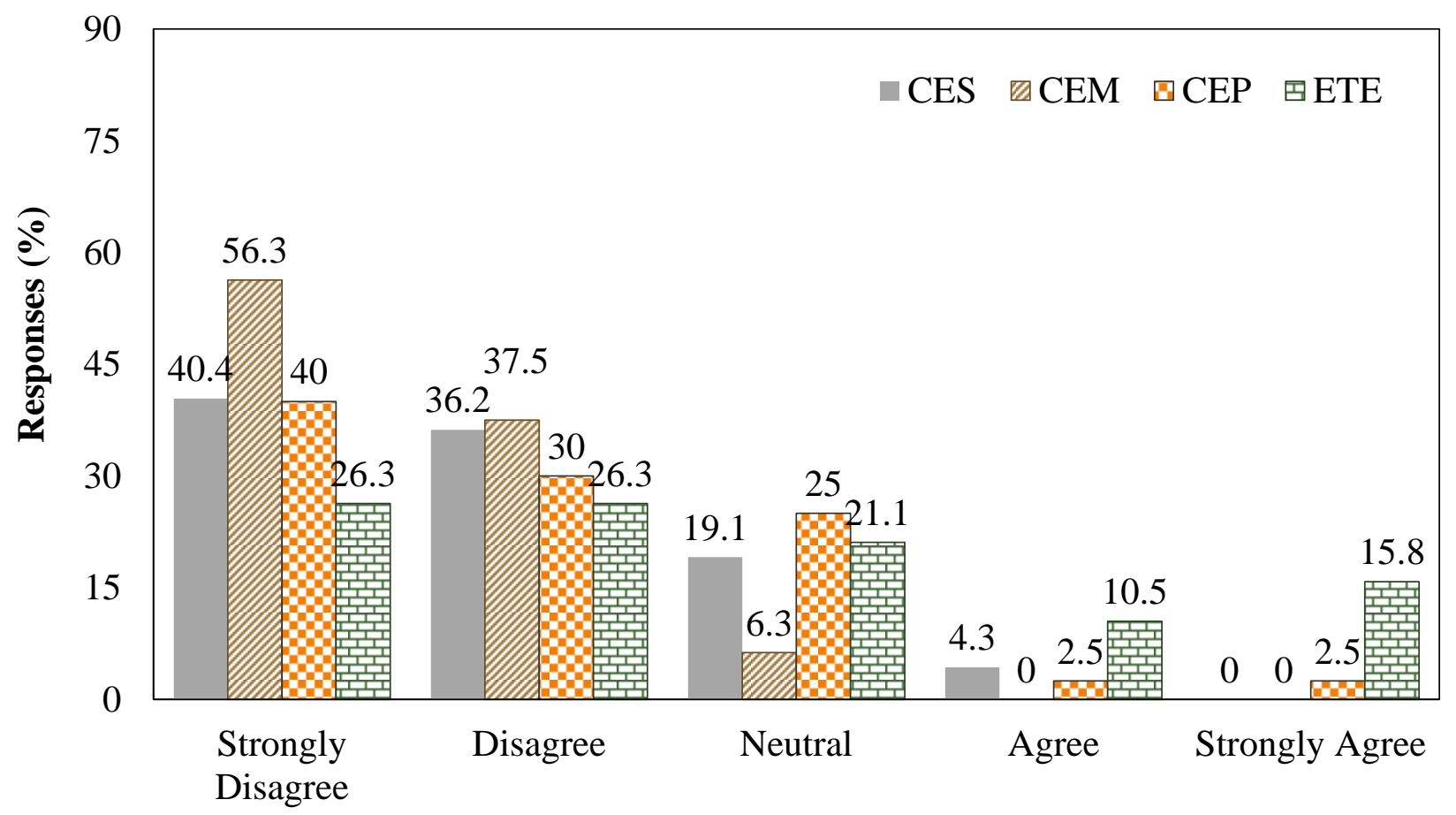

Figure 2: Responses Obtained for Pre-Teaching Survey Question No. 1 Related to Prior Knowledge of SHRP 2 Products.

Another aspect of the pre- and post-teaching surveys was to gauge the students' opinions on the importance of SHRP 2 prodcuts (i.e., Question No. 4 in both surveys). Figure 4 presents the survey results showing the students' responses to Question No. 4 related to the importance of SHRP 2 prodcuts. As presented in Figure 4, most of the students who selected neutral position in the pre-survey changed their selection in the post-survey to either agree or strongly agree positions (Figures $4 \mathrm{a}$ and $4 \mathrm{~b}$ ). The general trend by comparing the results in Figure 4a (preteaching survey) and Figure $4 \mathrm{~b}$ (post-teaching survey) suggests that the majority of students, regardless of their academic level, realized the importance of the these products immediately after learning about SHRP 2 products. These observations suggests that the implemented SHRP 2 vertical integration approach was successful at introducing SHRP 2 research products and instilling the importance of these products in the students at all levels. In other words, the integration approach was successful at fulfilling the objectives of this study. 


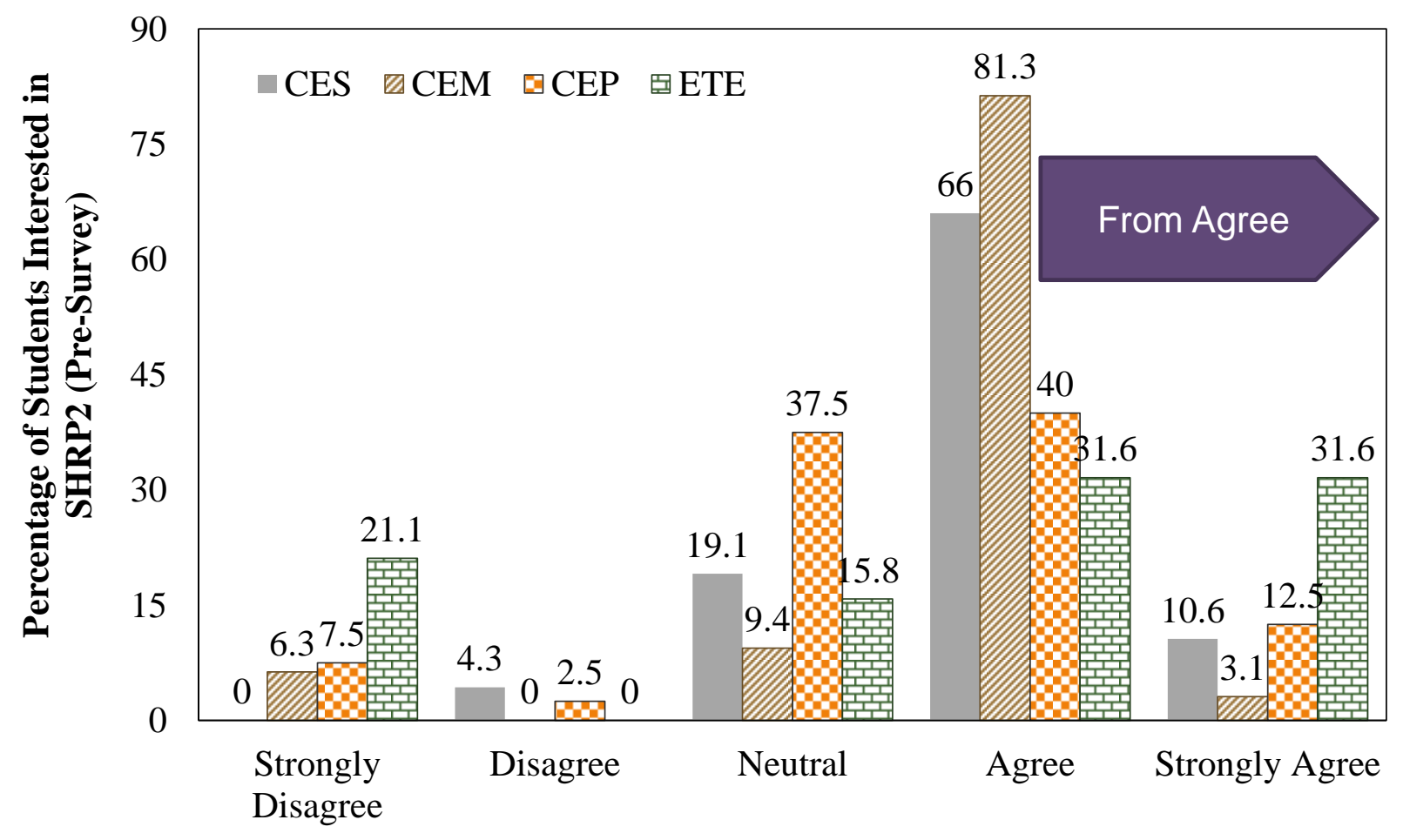

(a)

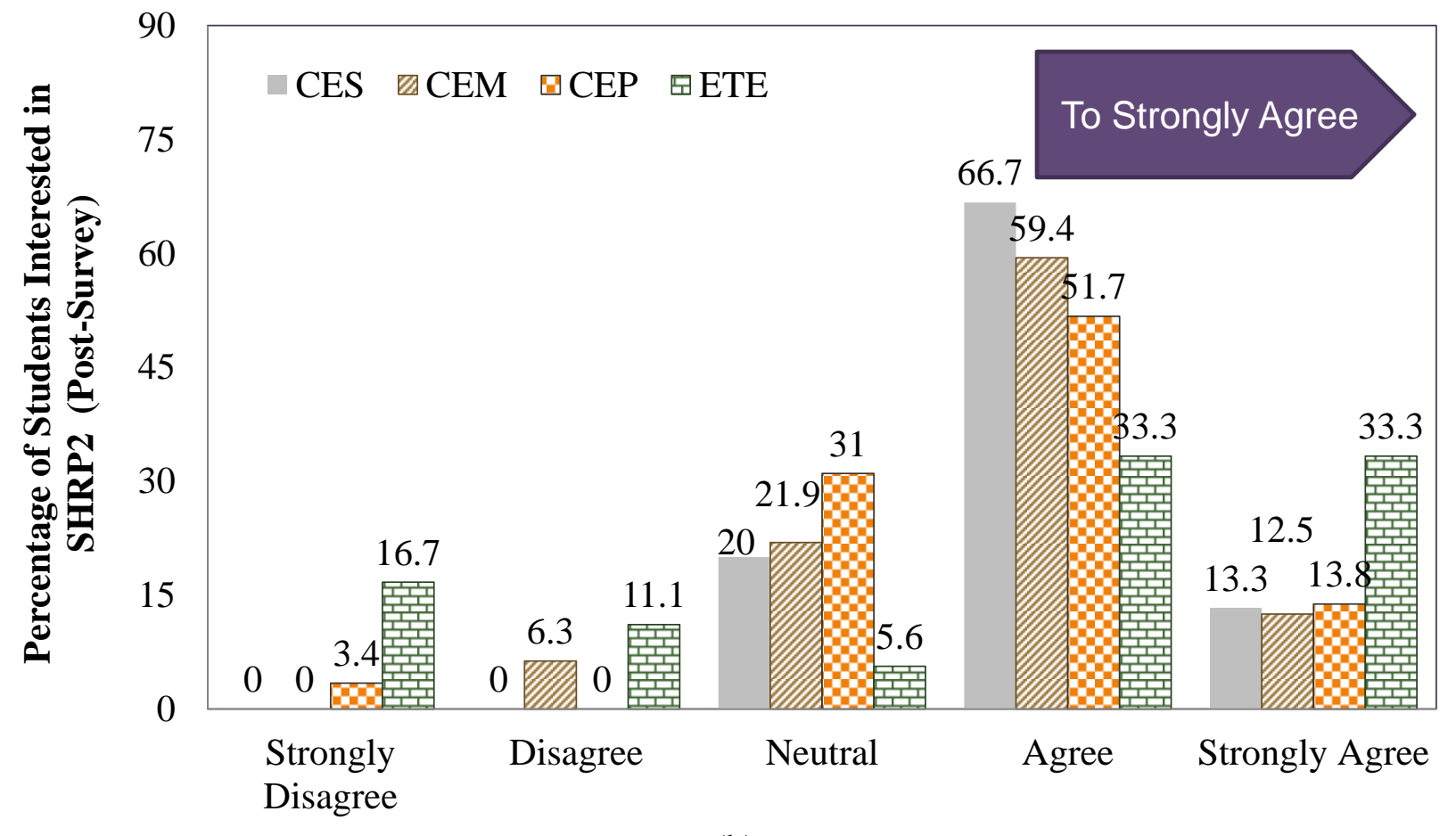

(b)

Figure 3: Responses Obtained from Pre- and Post-Teaching Surveys Related to Students' Interest in SHRP 2 Products: (a) Pre-Teaching Survey and (b) Post-Teaching Survey. 


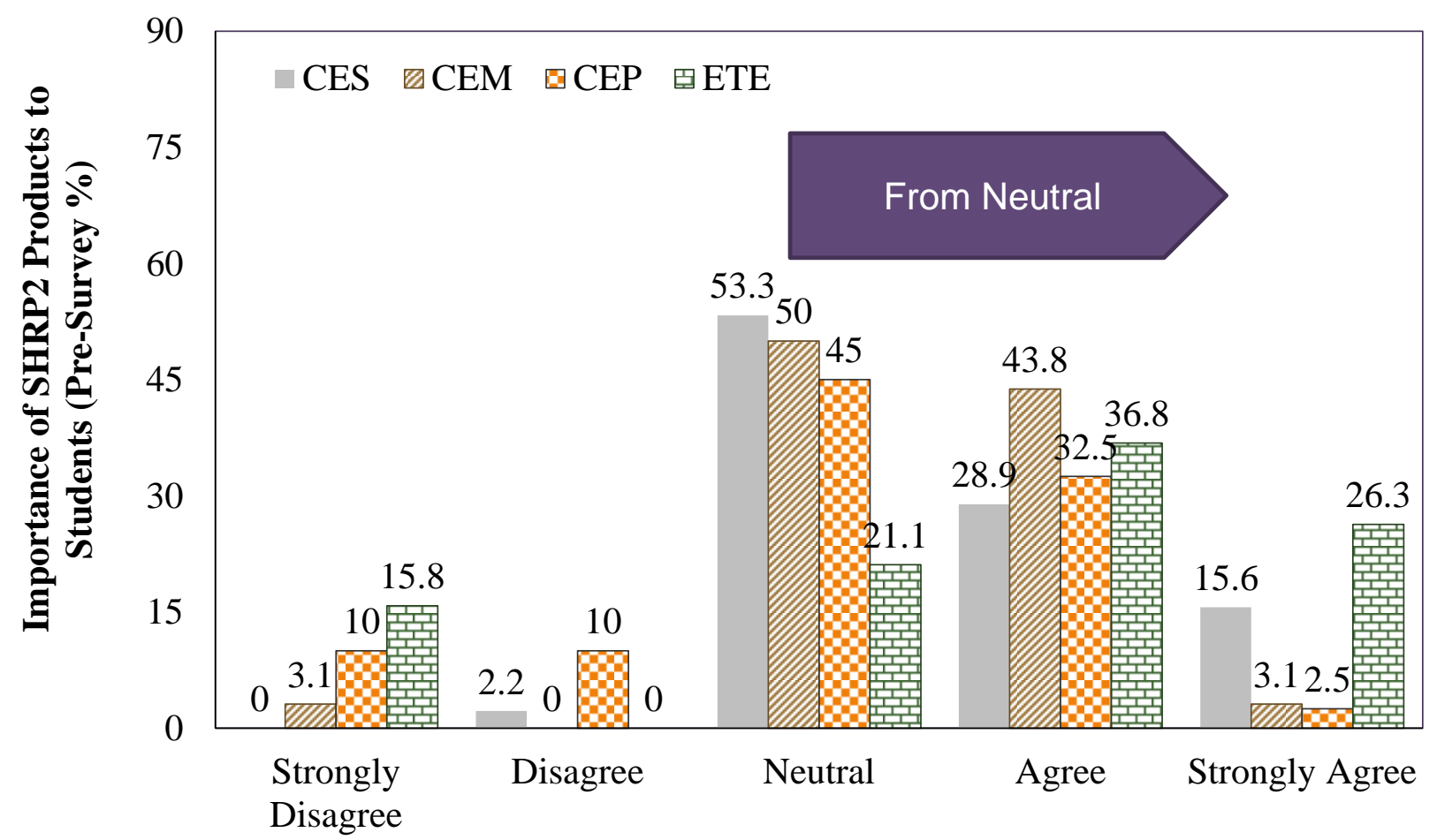

(a)

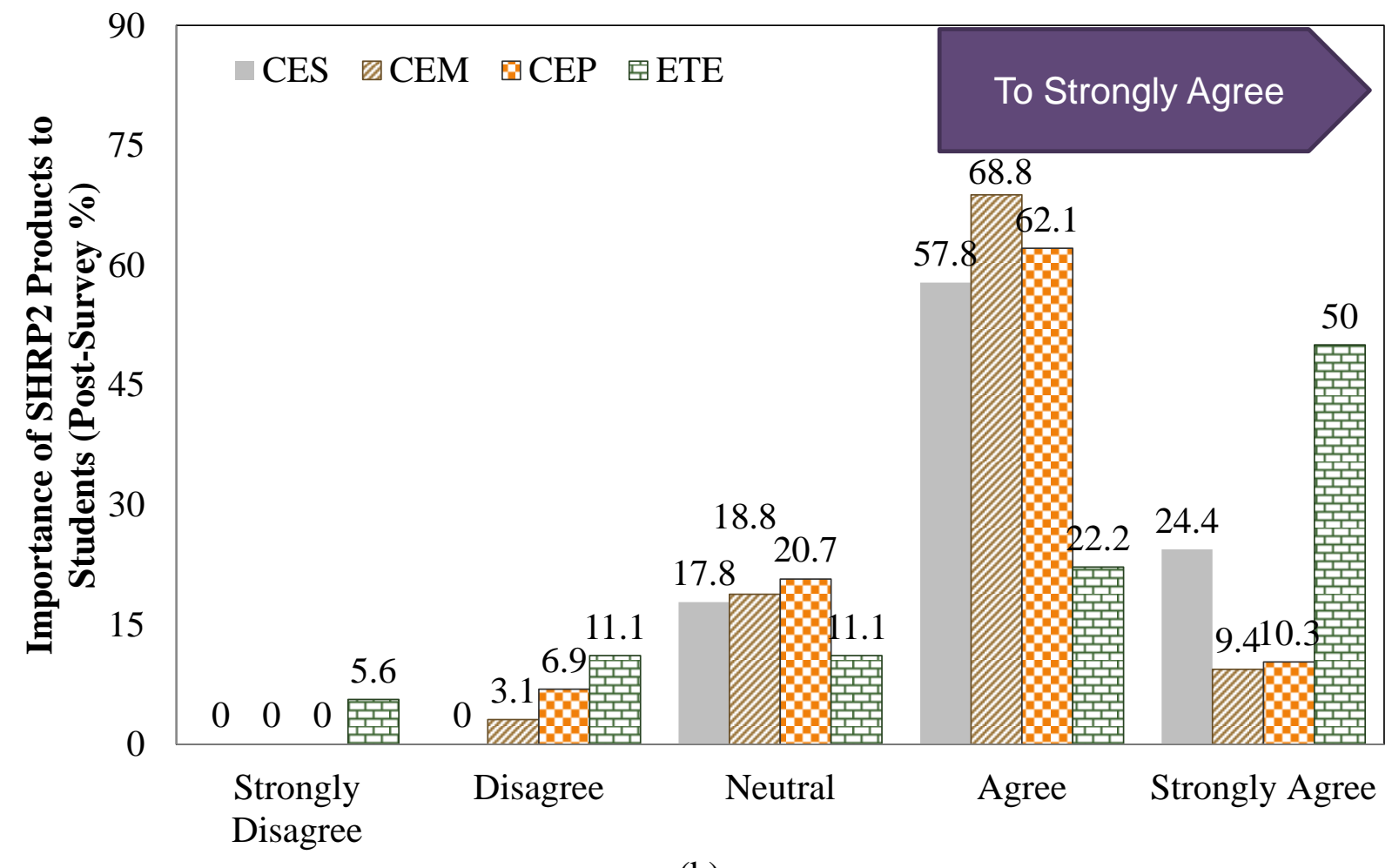

(b)

Figure 4: Responses Obtained from Pre- and Post-Teaching Surveys Related to Students' Opinions about Importance of SHRP 2 Products: (a) Pre-Teaching Survey and (b) Post-Teaching Survey. 


\section{CONCLUSIONS AND RECOMMENDATIONS}

This paper presented an approach to vertically integrate SHRP 2 products into Civil Engineering curricula. In this approach, several SHRP 2 products were incorporated into class modules and presented to students from all four academic levels (i.e., freshman, sophomore, junior, and senior/grad levels). The effectiveness of the proposed integration approach was evaluated by preparing pre- and post-teaching surveys that were conducted before and after teaching SHRP 2 modules. The prepared surveys focused on evaluating the students' prior knowledge of SHRP 2 products, their interest in learning SHRP 2 products, and their opinion on the importance of SHRP 2 products.

Based on the results presented and the analysis conducted as a part of this study, the following conclusions were drawn:

- $\quad$ The proposed SHRP 2 vertical integration approach was successful at implementing SHRP 2 products. This is believed to be the case because the survey results showed that the students were more interested in learning about SHRP 2 products after attending SHRP 2 modules. The survey results also showed that the importance of SHRP 2 products significantly increased in students at all levels after they learned the practical applications of these products.

- Since, students did not have any prior knowledge of the SHRP 2 program or research products, the proposed approach involved briefly introducing all the students from the four different academic levels to the same SHRP 2 introductory materials followed by the details of selected SHRP 2 products. While the details of selected SHRP 2 products varied at different academic levels, the introductory material at the beginning of the class facilitated the success of the vertical integration approach.

Furthermore, the following list provides recommendations for successful future implementation of the proposed SHRP 2 vertical integration approach. These recommendations are based on feedback from the SHRP 2 module instructors.

- It is recommended that future implementation of SHRP 2 products incorporate more of the SHRP 2 hands-on or field components.

- It is also recommended to develop group or individual class projects that focus on using SHRP 2 products.

- It is recommended to develop an "instruction manual" to educate instructors on the most suitable approach for presenting SHRP 2 products in class and laboratory settings. This will serve as the basis for continuous integration of these products.

- Inviting researchers and industry experts involved in SHRP 2 projects to serve as guest speakers is also recommended and encouraged.

\section{ACKNOWLEDGEMENT}

The authors would like to acknowledge the USDOT and the Federal Highway Administration for funding this study through the SHRP 2 Education Connection Program. 